\title{
Los derechos político-electorales de los ciudadanos en México a la sombra de una democracia y una tutela delegativas*
}

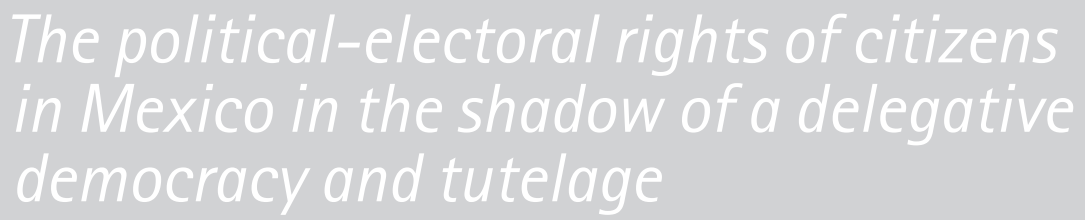

\section{Juan José Franco Cuervo**}

\begin{abstract}
RESUMEN
Este trabajo presenta la importancia internacional del derecho al voto como la manifestación del derecho humano a la libre determinación de los pueblos y explica la trascendencia de la participación ciudadana en la construcción de la democracia en México. Además, muestra que los derechos de participación politica no están protegidos integramente por un mecanismo legal que permita a los ciudadanos impugnar las violaciones a su derecho al voto, en razón que esa labor fue delegada a los partidos políticos desde la creación del sistema de medios de impugnación en materia electoral. De este modo, no sólo la democracia en México se encuentra delegada, en términos de la teoría de Guillermo O'Donnell, sino también el marco legal para la defensa de los derechos civiles. Esta situación es contraria a los tratados internacionales de los que México forma parte.
\end{abstract}

\section{PALABRAS CLAVE}

Democracia delegativa, derechos políticos, participación medios de impugnación electoral, voto.

\begin{abstract}
This work looks into the international importance of the right to vote as the manifestation of the human right to self-determination of peoples and explains the importance of citizen participation in the construction of democracy in Mexico. In addition, it shows that the rights of political participation are not fully protected by a legal mechanism that allows citizens to challenge violations of their right to vote, because this work was delegated to political parties since the creation of the media systems of ways of objecting in electoral matters. In this way, not only democracy in Mexico is delegated, in terms of Guillermo O'Donnell's theory, but also the legal framework for the defense of civil rights. This situation is contrary to the international treaties that Mexico is part of.
\end{abstract}

\section{KEYWORDS}

Delegative democracy, political rights, participation, Electoral trial, vote.

*Artículo recibido el 6 de agosto de 2017 y aceptado para su publicación el 30 de noviembre de 2017

** Unidad de Estudios de Posgrado, Facultad de Derecho, UNAM / Instituto Nacional Electoral (juanjocuervo@gmail. COm) ORCID: 0000-0002-5532-127X 
SUM ARIO

1. Introducción

2. Democracia y participación cívica

3. Los derechos político-electorales de los ciudadanos

4. La defensa de los derechos político-electorales en México

5. La democracia y la tutela de derechos delegativas

6. La tutela convencional de derechos político-electorales

7. Conclusión: La siguiente lucha democrática

\section{INTRODUCCIÓN}

El derecho al voto en sus dos vertientes, derecho a votar y a ser votado, es la forma más común como los pueblos contemporáneos autodeterminan su organización política. Esa libertad de autodeterminación en sociedad es un derecho humano reconocido por diversos instrumentos internacionales, por lo cual el derecho al voto debe reivindicarse, no sólo como un derecho ciudadano, sino como un derecho humano.

Desde el surgimiento de México como un país independiente, el voto ha sido la vía predominante por la cual sus ciudadanos han participado en la integración de los poderes públicos. Así, paulatinamente, han construido un Estado que contiene un régimen democrático, como explicó en su momento Guillermo 0’Donnell. ${ }^{1}$

Dentro de la evolución de dicho Estado, se gestó un sistema de medios de impugnación en materia electoral que, desde 1996, distribuyó la defensa del derecho humano al voto. De este modo, las violaciones a derechos individuales se impugnan directamente por el afectado, vía juicio para la protección de los derechos político-electorales del ciudadano (en adelante JDC) y las violaciones al proceso electoral, así como a los resultados de las elecciones, se impugnan por los contendientes electorales (partidos políticos, candidatos independientes, coaliciones, etcétera), principalmente vía apelación y juicio de inconformidad.

Con ese esquema, los ciudadanos ejercen su derecho al voto durante los procesos electorales. Después de emitirlo, todo lo que ocurra -defenderlo o no- compete a los partidos políticos. Es decir, la defensa del voto ciudadano se

\footnotetext{
1 O'Donnell, Guillermo, "Hacia un Estado de y para la Democracia", en Democracia/Estado/Ciudadanía: Hacia un Estado de y para la Democracia en América Latina, Perú, Programa de la Naciones Unidas para el Desarrollo (PNUD), 2008. [Consulta: 5 de agosto, 2017]. Disponible en: http://www.iidh.ed.cr/multic/UserFiles/Biblioteca/IIDHSeguridad/12_2010/be846c2a-a0e6-44d0-9fae-5d9d637df9ff.pdf
} 
encuentra en parte delegada, pues la facultad de impugnar las violaciones al proceso electoral y a los resultados electorales se transfirió a los partidos políticos.

Por tanto, este artículo tiene por objeto mostrar, a través de un proceso deductivo, que en México hay una democracia delegativa, pero también una defensa del voto delegativa, en manos de los partidos políticos. Esto debido a que un ciudadano no posee la legitimidad para controvertir posibles faltas al proceso electoral ni a sus resultados.

Para abundar en esta problemática, el Pacto de San José y el Pacto Internacional de Derechos Civiles y Políticos obligan a México a respetar el derecho humano al voto y a instrumentar, en favor del ciudadano, un recurso efectivo que restituya a las personas su derecho vulnerado. Esta situación, hasta ahora, sólo opera con el JDC por violaciones a derechos individuales.

Por ello, en este punto, cabe cuestionar: si el JDC no permite al ciudadano impugnar los resultados electorales, aun cuando las violaciones hayan incidido en su esfera jurídica, ¿acaso no debería existir un recurso individual efectivo para combatir violaciones a los actos posteriores a la emisión del sufragio?

La importancia de lo descrito radica en que, si dentro de una contienda electoral se da una violación al sufragio de los ciudadanos, éstos deberían poder defender la expresión de su voluntad e impugnar dicha violación mediante un recurso efectivo, en acato del marco convencional. Por tanto, se estima que esa defensa ciudadana del voto debería ser el siguiente ciclo evolutivo del JDC, sobre todo a partir de que, tras la reforma constitucional en materia de derechos humanos del 2011, en México, se cuenta con el marco jurídico necesario para implementar tales cambios.

\section{Democracia y Participación Cívica}

A lo largo de la historia, en nombre de la democracia, se han dividido o consolidado naciones enteras; se han combatido guerras; han surgido héroes y villanos; se han redactado miles de páginas y se ha formado un estilo de vida. Además, es común escuchar o leer en diversos medios que México es un país democrático. Sin embargo, paradójicamente, la Constitución Política de los Estados Unidos Mexicanos no define con precisión qué es la democracia, sino que sólo nos da pistas de cómo deberíamos ser en democracia.

Por ejemplo, el artículo tercero constitucional menciona que un criterio que orientará la educación es que sea democrática, considerando a la democracia no sólo como una estructura jurídica o un régimen político, sino como 
un sistema de vida fundado en el constante mejoramiento económico, social y cultural del pueblo.

Por su parte, el artículo 25 constitucional establece que la rectoría del desarrollo nacional corresponde al Estado, para garantizar que el mismo sea integral, sustentable, que fortalezca la soberanía y su régimen democrático, mediante el fomento al crecimiento económico, el empleo, una justa distribución de la riqueza, el pleno ejercicio de la libertad y la dignidad de los individuos, grupos y clases sociales.

Enseguida, el artículo 26 dice que el Estado organizará un sistema de planeación democrática del desarrollo nacional, mediante la participación de diversos sectores sociales, que recogerá las aspiraciones y demandas de la sociedad para incorporarlas al plan y los programas de desarrollo. ${ }^{2}$

Como se aprecia, la ley fundamental mexicana aspira a conformar un país democrático, pero no proporciona una definición precisa de qué se debe entender por democracia. No obstante, de los artículos mencionados, podemos inferir que para el constituyente mexicano la democracia se trata del fortalecimiento de la soberanía del Estado, mediante un crecimiento económico y la distribución de la riqueza, que permita a todos los mexicanos el ejercicio pleno de sus libertades individuales o colectivas.

Retomando el artículo 25 constitucional, la palabra soberanía "significa lo que está por encima o sobre todas las cosas, de super-sobre y omnia-todo, esto es, el poder que está sobre todos los demás poderes". ${ }^{3}$ La Real Academia de la Lengua define soberanía como el "poder supremo e ilimitado atribuido a la nación, al pueblo o al Estado, para establecer su constitución y adoptar las decisiones políticas fundamentales tanto en el ámbito interno como en el plano internacional". ${ }^{4}$

Así, la Constitución Política de los Estados Unidos Mexicanos busca fortalecer el poder del pueblo para autodeterminarse y gozar de sus libertades, mediante el crecimiento económico y la distribución de la riqueza. La Organización de las Naciones Unidas (oNU) estableció que "la democracia es un valor universal basado en la voluntad libremente expresada de los pueblos de determinar su propio sistema político, económico, social y cultural, y en su participación plena en

\footnotetext{
${ }^{2}$ Constitución Política de los Estados Unidos Mexicanos, México, 5 de febrero de 1917, Diario Oficial de la Federación, 24 de febrero, 2017.

${ }^{3}$ Guerrero González, Joel, "El concepto de soberanía en nuestra historia constitucional", en Memoria del IV Congreso de Historia del Derecho Mexicano (1986), México, unam, 1988. [Consulta: 5 de agosto, 2017]. Disponible en: https:// archivos.juridicas.unam.mx/www/bjv/libros/2/721/32.pdf

${ }^{4}$ Real Academia Española y Consejo General del Poder Judicial, Diccionario del español jurídico, Madrid, Espasa, 2016. [Consulta: 5 de agosto, 2017]. Disponible en: http://dej.rae.es/\#/entry-id/E225250
} 
todos los aspectos de su vida". ${ }^{5}$ En suma, la soberanía es el derecho de los pueblos para autodeterminarse; la soberanía es la democracia misma.

Bajo la óptica de la onu, la democracia tiene como sustento la participación de los individuos en los asuntos de su comunidad y tal participación se manifiesta mediante el voto. En consecuencia, el derecho a votar, en lo particular, y los derechos político-electorales, en lo general, son trascendentales para la comunidad internacional, en medida que afianzan al sistema democrático y a los derechos humanos en general.

Para lograr un crecimiento económico y la distribución de la riqueza -como aspira nuestra norma fundamental-, el Estado debe elaborar una planeación integral y sustentable que recoja las demandas de todos los sectores sociales e incorporarlas al plan y, de este modo, propiciar la participación. Así, la idea de participar en sociedad contiene el concepto clásico de democracia: del griego demos, pueblo, y kratos, poder y gobierno; es decir, la "forma de gobierno en la que el poder político es ejercido por los ciudadanos". ${ }^{6}$ En términos más simples, cuando los ciudadanos participan en el ejercicio del poder, se puede concebir una democracia.

Advertimos que esta primera idea puede parecer simplista, pero sólo tiene el fin de aproximarnos conceptualmente al tema, pues hoy en día las concepciones de democracia son tan variadas que referirnos a todas ellas ameritaría una obra por separado en extenso. Sobre ello, el sociólogo Alain Touraine expresó que la "Democracia es un concepto esencialmente disputado por actores que sustentan proyectos diversos de construcción social. Por ello, es tan difícil definirla y estudiarla, tanto como practicarla y promoverla". ${ }^{7}$

En cualquier caso, la participación es elemental para toda democracia. "Participar, en principio, significa tomar parte: convertirse uno mismo en parte de una organización que reúne a más de una sola persona. Pero también significa compartir algo con alguien o, por lo menos, hacer saber a otros alguna noticia. De modo que la participación es siempre un acto social: nadie puede participar de manera exclusiva, privada, para sí mismo.”8

\footnotetext{
${ }^{5}$ Resolución A/RES/62/7, Organización de las Naciones Unidas, Nueva York, 08 de noviembre de 2007. [Consulta: 5 de agosto, 2017]. Disponible en: http://www.un.org/es/comun/docs/?symbol=A/RES/62/7

${ }^{6}$ Real Academia Española, Diccionario de la lengua española, Madrid, Espasa, 2014. [Consulta: 5 de agosto, 2017]. Disponible en: http://dle.rae.es/?id=C9NX1Wr

7 Touraine, Alain, "Los caminos sinuosos", en La democracia en América Latina. Hacia una democracia de ciudadanas y ciudadanos. El debate conceptual sobre la democracia, Perú, Programa de las Naciones Unidas para el Desarrollo, 2004, p. 241. [Consulta: 5 de agosto, 2017]. Disponible en: http://www.cinu.org.mx/prensa/especiales/2005/2004/ informe_democracia/touraine_18\%20.pdf

${ }^{8}$ Merino, Mauricio, La participación ciudadana en la democracia, México, IFE, 2001, p. 9. [Consulta: 5 de agosto: 2017].
} 
De este modo, no es posible participar -o ser parte- donde no existe la organización de varias personas. De ahí que una democracia, donde los ciudadanos ejercen el poder político, exija que tales actores sean parte en la toma de decisiones. Sin embargo, lograr el consenso total de una sociedad para la toma de cada decisión puede resultar una labor casi imposible, pues hay tantas opiniones como personas.

De ahí que, por practicidad, la democracia se encauzó hacia la representación de los diversos grupos sociales, es decir, hacia la democracia representativa. La crítica de esta forma de democracia es que adolece cuando desplaza la participación ciudadana y concentra las decisiones en una cúpula, frecuentemente extraída de los partidos políticos, que puede tornarse autoritaria.

"De ahí el dilema: ¿democracia representativa o participativa?, ya que no basta con que haya elecciones libres de tacha, para que vivamos en democracia. Las elecciones populares son apenas el comienzo de una democracia, el mínimo grado de democracia. A partir de allí hay que construirla. Con ese y con otros métodos democráticos que comprendan a toda la sociedad y a todas sus dimensiones: la cultural, la económica y la política." ${ }^{9}$ Esto es, que aun cuando exista un modelo de representación social basado en la elección de representantes de cada sector de la sociedad, resulta necesaria la participación de una ciudadanía activa para consolidar la democracia.

Por ello, en los regímenes más actuales, se han sumado paulatinamente a la representación diversos mecanismos de participación social como el referéndum, el plebiscito y las consultas populares. Todos éstos sirven como cláusulas que aseguran los derechos fundamentales y permiten un control cotidiano de la validez y la legalidad de las decisiones del Estado, por parte de otros organismos públicos.

Guillermo 0'Donnell denominó a dichos mecanismos de control accountability y los vislumbró tanto verticales como horizontales; ${ }^{10}$ todos ellos son producto de la desconfianza ciudadana en cómo las instituciones públicas han ejercido el poder, por lo cual refuerzan las demandas ciudadanas sobre rendición de cuentas y el buen funcionamiento de la democracia.

\footnotetext{
Disponible en: https://archivos.juridicas.unam.mx/www/bjv/libros/1/499/3.pdf

${ }^{9}$ SÁCHICA, LuIS CARlos, Democracia, representación y participación, Costa Rica, Instituto Interamericano de Derechos Humanos - Centro de Asesoría y Promoción Electoral (Capel), 1985, pp. 11 y 12. [Consulta: 5 de agosto, 2017]. Disponible en: https://archivos.juridicas.unam.mx/www/bjv/libros/5/2100/2.pdf

${ }^{10}$ O'Donnell, Guilermo, "Rendición de cuentas horizontal y nuevas poliarquias", Revista Nueva Sociedad, núm. 152, pp. 143-167.
} 
Como se puede apreciar, la democracia se puede concebir de diferentes maneras e implica diversas aristas, por lo cual, nos vemos en la necesidad de centrarnos en una sola definición, para delimitar el objeto de estudio del presente artículo. Éste, al tratarse de aspectos jurídico-electorales, exige un contexto comicial.

Por esa razón, nos apegaremos a la definición de democracia del jurista Jorge Carpizo, quien afirmó: "Es el sistema en el cual los gobernantes son electos periódicamente por los electores; el poder se encuentra distribuido entre varios órganos con competencias propias y con equilibrios y controles entre ellos, así como responsabilidades señaladas en la Constitución con el objeto de asegurar los derechos fundamentales que la propia Constitución reconoce directa o indirectamente". ${ }^{11}$

Dicha definición no considera la visión económica que se mencionó con antelación y se constriñe al ámbito político-electoral, sin embargo, su relevancia estriba en dejar patente que el poder político se ha de ejercer con el fin de asegurar los derechos fundamentales. Además, incluye los equilibrios y controles entre los órganos de poder, lo cual se aproxima a lo que explicado 0'Donnell respecto a la accountability.

Aquí, cobra relevancia Alberto J. Olvera, cuando dice: "En efecto, en la práctica sólo los derechos políticos se vinculan directamente con la democracia. La democracia se funda en los derechos políticos, existe en su reconocimiento y deja de existir en su anulación". ${ }^{12}$

Para la teoría democrática, la premisa es que el pueblo participe, por ello, los ciudadanos tienen derecho a votar, es decir, a participar. La forma en que participan es a través de elecciones periódicas con las cuales se integran los poderes públicos. De este modo, la emisión del voto ciudadano será el reflejo de la autodeterminación del pueblo. En consecuencia, la defensa de esos votos será la defensa del derecho humano a autodeterminarse, será la defensa de la soberanía, la defensa de la democracia.

\section{LOS DERECHOS POLITICO-ELECTORALES DE LOS CIUDADANOS}

Principalmente, los artículos 40 y 41 de la Constitución Política de los Estados Unidos Mexicanos establecen cuáles son las formas de gobierno y la vía de

\footnotetext{
${ }^{11}$ Carpizo, Jorge, Concepto de democracia y sistema de gobierno en América Latina, México, unam, 2007, p. 100. [Consulta: 5 de agosto, 2017]. Disponible en: https://archivos.juridicas.unam.mx/www/bjv/libros/5/2473/6.pdf

12 Olvera, Alberto, Ciudadanía y democracia, México, IFE, 2008, p. 44. [Consulta: 5 de agosto, 2017]. Disponible en: https://archivos.juridicas.unam.mx/www/bjv/libros/8/3562/6.pdf
} 
participación ciudadana. El artículo 40 menciona que "es voluntad del pueblo mexicano constituirse en una república representativa, democrática, federal, compuesta de estados libres y soberanos en todo lo concerniente a su régimen interior; pero unidos en una federación establecida según los principios de esta ley fundamental". ${ }^{13}$

Por otra parte, el artículo 41 dice que el pueblo ejerce su soberanía por medio de los Poderes de la Unión, en armonía de un pacto federal que respeta los regímenes interiores de los estados. Además, la renovación de los poderes Legislativo y Ejecutivo se realizará mediante elecciones libres, auténticas y periódicas, donde se aprecia que la Constitución confiere a la participación ciudadana la integración de dichos poderes.

El derecho a esa participación para conformar los poderes públicos se integra por un conjunto de prerrogativas irrenunciables que las personas gozan para participar de manera individual o colectiva en la toma de decisiones. Éstas son los derechos políticos.

Tales derechos tienen un estatus internacional de derechos humanos pero con el matiz de que en todos los países se comienzan a ejercer cuando las personas cumplen ciertos requisitos de edad y residencia, principalmente, según las reglas de cada Estado. Es decir, cuando las personas se consideran como ciudadanos. Por ello, estos derechos se identifican como derechos ciudadanos, derechos civiles o derechos civiles y políticos.

Aguilar León sostiene que "por lo que se refiere a la conceptualización de los derechos políticos, desde el punto de vista constitucional, son el grupo de atributos de la persona que hacen efectiva su participación como ciudadano de un determinado Estado. En otros términos, es el conjunto de facultades que hacen posible la participación del ciudadano en la vida política del Estado al cual pertenecen". ${ }^{14}$

Dentro del marco legal mexicano, los principales derechos políticos son votar, ser votado, derecho de reunión y de asociación política, derecho de petición, derecho a la información, libertad de expresión y libertad de imprenta,

196 los cuales adquieren el nombre de derechos político-electorales dentro del contexto de la celebración de elecciones.

Sin embargo, la interpretación proveniente del Tribunal Electoral del Poder Judicial de la Federación no se restringe a valorar sólo los derechos

\footnotetext{
${ }^{13}$ Constitución Política de los Estados Unidos Mexicanos, México, 5 de febrero de 1917, Diario Oficial de la Federación, 24 de febrero, 2017.

${ }^{14}$ Aguilar León, Norma Inés, "Los derechos políticos como derechos humanos en México", en Derecho Electoral. Temas de Actualidad, México, Porrúa - UnAm, 2011, p. 252.
} 
político-electorales. El tribunal ha establecido, de forma sistemática, que todos los derechos fundamentales que estén ligados al proceso electoral y guarden relación con el ejercicio de los derechos señalados anteriormente, deben considerarse como derechos político-electorales y ameritan que el JDC los tutele. ${ }^{15} \mathrm{La}$ finalidad de ese criterio jurisdiccional es potenciar los derechos mediante una interpretación extensiva, en beneficio de los derechos humanos.

En este contexto, el derecho al voto se considera como el principal derecho político-electoral, por estar permanentemente vinculado a las elecciones. El sistema electoral mexicano orbita en torno al ejercicio del voto ciudadano y es su base principal.

El derecho al voto, conocido también como sufragio, tiene una doble vertiente: funge como derecho y como obligación. Como derecho, es fundamental para que los ciudadanos participen en la integración de los poderes públicos $\mathrm{y}$, como obligación, constituye un deber ciudadano para participar en los asuntos que atañen a la comunidad. Lo anterior tiene sustento en los artículos 35, 39, 41 y 116 de la Constitución, preceptos que consagran la potestad del pueblo para gobernarse a sí mismo, la prerrogativa a ser votado y el derecho a integrar los Poderes de la Unión para el ejercicio de la soberanía, mediante la elección libre, auténtica y periódica de los ciudadanos.

\section{La defenSa de los deReChos político-electorales en MÉxico}

Para tutelar los derechos político-electorales existe un sistema impugnativo que contempla la Ley General del Sistema de Medios de Impugnación en Materia Electoral. ${ }^{16}$ Éste tiene la finalidad de 1) Garantizar los principios de constitucionalidad y legalidad de los actos y resoluciones electorales; 2) dar definitividad a las distintas etapas de los procesos electorales, y 3) garantizar la protección de los derechos políticos de los ciudadanos de votar, ser votados y de asociación, como lo dispone la fracción 6 , del artículo 41 constitucional. ${ }^{17}$

Dicha ley detalla los procedimientos para la interposición de diversos juicios y recursos, a saber: el recurso de revisión, el recurso de apelación, el juicio de inconformidad (JIN), el recurso de reconsideración, el juicio de revisión

\footnotetext{
${ }^{15}$ Jurisprudencia 36/2002, Justicia Electoral. Revista del Tribunal Electoral del Poder Judicial de la Federación, suplemento 6, tercera época, año 2003, pp. 40-41.

16 "Ley General del Sistema de Medios de Impugnación en Materia Electoral, México, 22 de noviembre de 1996", Diario Oficial de la Federación, 23 de mayo, 2014.

${ }^{17}$ Constitución Política de los Estados Unidos Mexicanos, México, 5 de febrero de 1917, Diario Oficial de la Federación, 24 de febrero, 2017.
} 
constitucional, el juicio para dirimir los conflictos o diferencias laborales entre el $\mathrm{INE}^{18} \mathrm{y}$ sus servidores (JLI), así como el juicio para la protección de los derechos político-electorales del ciudadano (JDC).

Estos mecanismos de impugnación combaten distintos tipos de actos, provenientes de autoridades en materia electoral, que se estiman violadores de los principios, derechos, reglas o procesos comiciales. Centraremos nuestra atención en el JDC debido a que es el medio de impugnación con el cual cuentan los ciudadanos.

La Ley General del Sistema de Medios de Impugnación en Materia Electoral, en su artículo 79, establece las causales de procedencia e indica que "sólo procederá cuando el ciudadano por sí mismo y en forma individual o a través de sus representantes legales, haga valer presuntas violaciones a sus derechos de votar y ser votado en las elecciones populares, de asociarse individual y libremente para tomar parte en forma pacífica en los asuntos políticos y de afiliarse libre e individualmente a los partidos políticos". ${ }^{19}$

En este sentido, queda claro que la interposición del JDC corresponde únicamente a los ciudadanos que se aquejen de violaciones directas a sus derechos político-electorales. Mercader Díaz De León esgrime sobre el JDC: “en nuestro concepto, es el instrumento legal con que cuentan los ciudadanos para hacer valer las presuntas laceraciones a sus derechos político-electorales consignados en la Constitución y en la ley, a fin de que puedan ser restituidos por las autoridades jurisdiccionales competentes". ${ }^{20}$

El resto de medios de impugnación están en manos de los partidos políticos, salvo el JLI que toca al trabajador del INE. Por ello, los partidos políticos tienen gran relevancia durante los procesos electorales, pues concentran la mayor parte del peso impugnativo, y en general, de la defensa de los derechos políticos.

Lo anterior proviene del artículo 41 constitucional, el cual dispone que la renovación de los Poderes Ejecutivo y Legislativo se realice mediante elecciones libres, auténticas y periódicas. Pero, además, establece en su base 1 que los partidos políticos tienen como fin promover la participación del pueblo en la vida democrática; contribuir a la integración de la representación nacional y, como organizaciones, hacer posible el acceso de los ciudadanos al ejercicio del

\footnotetext{
${ }_{18}$ Instituto Nacional Electoral.

19 "Ley General del Sistema de Medios de Impugnación en Materia Electoral, México, 22 de noviembre de 1996", Diario Oficial de la Federación, 23 de mayo, 2014.

${ }^{20}$ Mercader Diaz De León, Antonio, Derecho electoral mexicano: el juicio electoral ciudadano y otros medios de control constitucional, México, Porrúa, 2006, pp. 107-108.
} 
poder público, de acuerdo con los programas, principios e ideas que postulan y mediante el sufragio universal, libre, secreto y directo. ${ }^{21}$

Con dicho precepto, el poder constituyente mexicano nos dijo que la forma de organización política nacional es la democracia, pero, además, que el principal mecanismo de participación colectiva son los partidos políticos, a quienes se les delegó en gran medida la organización ciudadana y la defensa del voto.

\section{La DEMOCRACIA Y LA TUTELA DE DERECHOS DELEGativas}

Guillermo 0’Donnell explicó que "las democracias delegativas se basan en la premisa de quien sea que gane una elección presidencial tendrá el derecho a gobernar como él (o ella) considere apropiado, restringido sólo por la dura realidad de las relaciones de poder existentes y por un período en funciones limitado constitucionalmente". ${ }^{22}$

Para dicho autor, una democracia delegativa tiene la característica de que, una vez es electo un gobernante, se le considera como la encarnación del país mismo, el principal custodio e intérprete de los intereses de una colectividad. De esta manera, se le permite actuar de forma unilateral, e incluso autoritaria. Por tanto, cualquier mecanismo de rendición de cuentas le representa un obstáculo.

Estas democracias se distinguen por ser fuertemente mayoritarias, buscan formar una ventaja electoral amplia, a modo de revestir al candidato electo de legitimidad para la toma de decisiones. En las democracias delegativas,

se espera que los votantes elijan, independientemente de sus identidades y afiliaciones, al individuo más apropiado para hacerse responsable del destino del país. En las DD las elecciones constituyen un acontecimiento muy emocional y en donde hay mucho en juego: los candidatos compiten por la posibilidad de gobernar prácticamente sin ninguna restricción salvo las que imponen las propias relaciones de poder no institucionalizadas. Después de la elección, los votantes (quienes delegan) deben convertirse en una audiencia pasiva, pero que vitoree lo que el presidente haga. ${ }^{23}$

\footnotetext{
21 "Constitución Política de los Estados Unidos Mexicanos, México, 5 de febrero de 1917", Diario Oficial de la Federación, 24 de febrero, 2017.

22 O'Donnell, Guillermo, "Democracia Delegativa", Journal of Democracy en Español, vol. 5, núm. 1, p. 12.

${ }^{23}$ O'Donnell, Guillermo, "Democracia Delegativa", Journal of Democracy en Español, vol. 5, núm. 1, p. 13.
} 
México tiene una democracia delegativa, en razón de que cada gobernante, ya sea a nivel local o federal, suele buscar la construcción de una mayoría, mediante alianzas electorales y parlamentarias. Esto para efecto de contar con la legitimidad necesaria en la toma de decisiones y ser restringido únicamente por las relaciones de poder preexistentes.

$\mathrm{Su}$ actuar se vuelve unilateral, guarda distancia de las consultas populares, los referéndums, plebiscitos o cualquier mecanismo de accountability, pues cuenta con una delegación de funciones legítima, por la elección de una mayoría, que le permite tomar decisiones sin consultarlas con nadie más que su gabinete.

Sin embargo, el fenómeno de democracia delegativa no es privativo de los gobernantes, sino que se extiende hasta los líderes de los partidos políticos. Estos últimos, aunque poseen un régimen de democracia interna distinto en cada instituto político, coinciden en que al momento de elegir a sus dirigencias, los líderes electos actúan como una democracia delegativa.

En consecuencia, los militantes y simpatizantes del partido le confieren al líder el destino del partido político, el cual es administrado sin restricciones, salvo aquéllas inherentes a las relaciones de poder con las cuales interactúa.

El dirigente partidista construye o destruye alianzas, ya sea con otros partidos políticos o con gobiernos; dicta las políticas a seguir; traza un plan de trabajo; influye de forma determinante en la designación de candidatos; es la encarnación del partido mismo. Su imagen es de custodio e intérprete de los intereses colectivos, lo cual incluye tomar la decisión de defender, o no, el sufragio emitido por sus votantes, dependiendo la coyuntura política.

Esto se debe a que, durante los procesos electorales, una vez que fue emitido el voto de los ciudadanos durante la jornada electoral, los ciudadanos están impedidos jurídicamente para interponer medios de impugnación en defensa de su voto. Esa función fue delegada a los líderes y representantes de los partidos políticos, por medio del juicio de inconformidad (JiN).

El artículo 50 de la Ley General del Sistema de Medios de Impugnación en 200 Materia Electoral, establece que son impugnables a través del JIN:

a) En la elección de presidente de los Estados Unidos Mexicanos:

I. Los resultados consignados en las actas de cómputo distrital respectivas, por nulidad de la votación recibida en una o varias casillas o por error aritmético, $\mathrm{y}$

II. Por nulidad de toda la elección. 
b) En la elección de diputados por el principio de mayoría relativa:

I. Los resultados consignados en las actas de cómputo distrital, las declaraciones de validez de las elecciones y el otorgamiento de las Constancias de Mayoría y Validez respectivas, por nulidad de la votación recibida en una o varias casillas o por nulidad de la elección;

II. Las determinaciones sobre el otorgamiento de las Constancias de Mayoría y Validez respectivas; y

III. Los resultados consignados en las actas de cómputo distrital, por error aritmético.

c) En la elección de diputados por el principio de representación proporcional, los resultados consignados en las actas de cómputo distrital respectivas:

I. Por nulidad de la votación recibida en una o varias casillas; o

II. Por error aritmético.

d) En la elección de senadores por el principio de mayoría relativa y de asignación a la primera minoría:

I. Los resultados consignados en las actas de cómputo de entidad federativa, las declaraciones de validez de las elecciones y el otorgamiento de las Constancias de Mayoría y Validez o de Asignación de primera minoría respectivas, por nulidad de la votación recibida en una o varias casillas o por nulidad de la elección;

II. Las determinaciones sobre el otorgamiento de las Constancias de Mayoría y Validez o de Asignación de primera minoría respectivas; y III. Los resultados consignados en las actas de cómputo de entidad federativa, por error aritmético.

e) En la elección de senadores por el principio de representación proporcional, los resultados consignados en las actas de cómputo de entidad federativa respectivas:

I. Por nulidad de la votación recibida en una o varias casillas; o

II. Por error aritmético. ${ }^{24}$

24 "Ley General del Sistema de Medios de Impugnación en Materia Electoral, México, 22 de noviembre de 1996", Diario Oficial de la Federación, 23 de mayo, 2014. 
En suma, el Jin es el medio de impugnación que tutela los resultados, una vez que las autoridades electorales contabilizan los votos de los ciudadanos. Sin embargo, el artículo 54 de la misma ley impone que el JIN sólo podrá ser promovido por los partidos políticos y, en determinados casos, por los candidatos; nunca por los ciudadanos.

Así, el dirigente partidista cuenta con la potestad delegada de decidir si impugna o no el resultado de una elección, aun cuando durante una jornada electoral se hayan vislumbrado y documentado violaciones serias al voto, que hayan trascendido al resultado de la elección y afecten la esfera jurídica del ciudadano votante.

En estos casos el JDC no es procedente, pues dicho juicio no contempla que los ciudadanos impugnen los resultados electorales. Una vez que el voto ciudadano fue emitido, el destino de su sufragio corre a cuenta de los partidos políticos.

\section{La tUTEla CONVENCIONAL DE DERECHOS POLITICO-ELECTORALES}

Existen diversos instrumentos internacionales que tutelan los derechos político-electorales y son de aplicación en el régimen jurídico mexicano. Uno de ellos es la Declaración Americana de Derechos y Deberes del Hombre, firmada en Bogotá, Colombia, en 1948. ${ }^{25}$ Respecto a los derechos políticos, esta declaración menciona en sus artículos 2, 3, 4, 20, 21, 22 y 24 que, en los países americanos firmantes, todas las personas tienen derecho a reunirse y organizarse para participar del gobierno de su país, de forma directa o a través de representantes. Asimismo, tienen derecho a participar en las elecciones y en la dirección de los asuntos públicos, así como a votar y ser votados en elecciones auténticas mediante voto universal y secreto, que garantice la libre voluntad de expresión de los electores.

Más tarde, la Organización de las Naciones Unidas (onu) reconoció los derechos político-electorales y los incorporó a la Declaración Universal de los De202 rechos Humanos, aprobada el 10 de diciembre de 1948, mediante la resolución 217 (3) de su Asamblea General.

Dicha declaración, en sus artículos 20 y 21, estableció que toda persona tiene derecho a la libertad de reunión y de asociación pacíficas, así como a

\footnotetext{
25 "Declaración Americana de los Derechos y Deberes del Hombre, Colombia, 1948", Organización de Estados Americanos. [Consulta: 5 de agosto, 2017]. Disponible en: http://www.oas.org/es/cidh/mandato/Basicos/declaracion.asp
} 
participar en el gobierno de su país, directamente o por medio de representantes libremente escogidos.

Además, "la voluntad del pueblo es la base de la autoridad del poder público; esta voluntad se expresará mediante elecciones auténticas que habrán de celebrarse periódicamente, por sufragio universal e igual y por voto secreto $u$ otro procedimiento equivalente que garantice la libertad del voto". ${ }^{26}$

Para fortalecer el reconocimiento de tales derechos, esta declaración agregó en su artículo 8 que "toda persona tiene derecho a un recurso efectivo ante los tribunales nacionales competentes, que la ampare contra actos que violen sus derechos fundamentales reconocidos por la constitución o por la ley". Es decir, junto a los derechos político-electorales, se estableció la existencia de un derecho a tener un recurso jurídico efectivo que los tutele.

Más adelante, el Pacto Internacional de Derechos Civiles y Políticos incluyó los derechos político-electorales y estableció:

Artículo 2

1. Cada uno de los Estados Parte en el presente Pacto se compromete a respetar y a garantizar a todos los individuos que se encuentren en su territorio y estén sujetos a su jurisdicción los derechos reconocidos en el presente Pacto, sin distinción alguna de raza, color, sexo, idioma, religión, opinión política o de otra índole, origen nacional o social, posición económica, nacimiento o cualquier otra condición social.

2. Cada Estado Parte se compromete a adoptar, con arreglo a sus procedimientos constitucionales y a las disposiciones del presente Pacto, las medidas oportunas para dictar las disposiciones legislativas o de otro carácter que fueren necesarias para hacer efectivos los derechos reconocidos en el presente Pacto y que no estuviesen ya garantizados por disposiciones legislativas o de otro carácter [...]

Artículo 25

Todos los ciudadanos gozarán, sin ninguna de las distinciones mencionadas en el artículo 2, y sin restricciones indebidas, de los siguientes derechos y oportunidades:

a) Participar en la dirección de los asuntos públicos, directamente o por medio de representantes libremente elegidos;

\footnotetext{
${ }^{26}$ Naciones Unidas, "Declaración Universal de Derechos Humanos, Nueva York, 1948", Naciones Unidas. [Consulta: 5 de agosto, 2017]. Disponible en: http://www.un.org/es/documents/udhr/
} 
b) Votar y ser elegidos en elecciones periódicas, auténticas, realizadas por sufragio universal e igual y por voto secreto que garantice la libre expresión de la voluntad de los electores;

c) Tener acceso, en condiciones generales de igualdad, a las funciones públicas de su país. ${ }^{27}$

Posterior a este pacto, del 7 al 22 de noviembre de 1969, se celebró en la ciudad de San José, Costa Rica, la Conferencia Especializada Interamericana Sobre Derechos Humanos -también llamada Pacto de San José-. Ésta derivó en la firma de una Convención Americana de Derechos Humanos que vinculó a México hasta el 24 de marzo de 1981. En ella se ratificaron los deberes asumidos en diversos instrumentos internacionales, con miras a crear condiciones que permitieran a todas las personas gozar de sus derechos económicos, sociales, culturales, civiles y políticos.

El Pacto de San José desarrolla, en su artículo 1, la obligación de respetar los derechos por parte de los Estados Parte; en su artículo 2, establece el deber de adoptar disposiciones de derecho interno, que obliga a todos los Estados firmantes a implementar las medidas legislativas o de otro carácter que fueran necesarias para hacer efectivos los derechos y libertades asumidos en la convención.

Además, en su artículo 16, establece la libertad de asociación y, en el artículo 23, los derechos políticos. A este reconocimiento se suma el artículo 25, que fundamenta la protección judicial, esto es, el derecho de toda persona a tener un recurso sencillo, rápido y efectivo ante los jueces o tribunales competentes, que la ampare contra actos que violen sus derechos fundamentales reconocidos por la Constitución, la ley o la convención. ${ }^{28}$

En otro momento, la Conferencia Mundial de Derechos Humanos celebrada en Viena, Austria, del 14 al 25 de junio de 1993, derivó en la firma de 171 Estados miembros de la ONU, de una estrategia común para fortalecer el trabajo en favor de los derechos humanos globales. Esta estrategia se denominó Declaración y Programa de Acción de Viena y en ella se estableció que "los derechos humanos y las libertades fundamentales son patrimonio innato de todos los seres humanos; su promoción y protección es responsabilidad primordial

\footnotetext{
27 "Pacto Internacional de Derechos Civiles y Políticos, Nueva York, 1966", Oficina del Alto Comisionado de los Derechos Humanos. [Consulta: 5 de agosto, 2017]. Disponible en: http://www.ohchr.org/SP/Professionallnterest/ Pages/CCPR.aspx

28 "Convención Americana sobre Derechos Humanos (Pacto de San José), Costa Rica, 1969", Organización de Estados Americanos. [Consulta: 5 de agosto, 2017]. Disponible en: http://www.oas.org/dil/esp/tratados_B-32_Convencion_ Americana_Sobre_Derechos_Humanos.htm
} 
de los gobiernos". ${ }^{29}$ Asimismo, se reconoce el "derecho de los pueblos a adoptar cualquier medida legítima, de conformidad con la Carta de las Naciones Unidas, encaminada a realizar su derecho inalienable a la libre determinación". ${ }^{30}$

En otras palabras, la comunidad internacional reconoció el derecho inalienable de todos los seres humanos para autodeterminar su forma de organización social, lo cual incluye el derecho al voto. Además, la declaración asentó que "la denegación del derecho a la libre determinación constituye una violación de los derechos humanos y [se] subraya la importancia de la realización efectiva de este derecho". ${ }^{31}$

Como puede apreciarse, el sistema jurídico mexicano ha tenido un influjo internacional muy nutritivo. La multiplicidad de tratados firmados en materia de derechos humanos amplía el horizonte de derechos político-electorales y la expectativa democrática.

Por su parte, los jueces mexicanos están obligados a supervisar, en su jurisdicción, que los actos de autoridad respeten los convenios internacionales vinculantes a nuestro país. Esta actividad se denomina control de convencionalidad y se refiere a la obligación de los jueces nacionales para aplicar el derecho internacional en la solución de las controversias.

Sin embargo, al relacionar los tratados internacionales con el marco jurídico nacional, advertimos que el ciudadano en México no cuenta con un recurso efectivo que lo ampare, en particular, contra violaciones a su derecho al voto una vez que éste fue emitido. El ciudadano no está legitimado para interponer el JIN, y el JDC no abarca este supuesto impugnativo.

Por esa razón, el sistema electoral mexicano contraviene las normas internacionales, al dejar desprotegidas a las personas, sin un recurso efectivo que les permita realizar la defensa de su derecho humano al voto ${ }^{32}$ emitido.

En esta situación, la labor de los juzgadores resulta de especial trascendencia en materia político-electoral. Ante la pasividad de los legisladores en

\footnotetext{
${ }^{29}$ Conferencia Mundial de Derechos Humanos, Declaración y programa de acción de Viena, 12 de julio de 1993, [Consultada 5 de junio de 2018], [Disponible en: http://www.ohchr.org/Documents/Events /OHCHR20/VDPA_ booklet_Spanish.pdf]

${ }^{30}$ Conferencia Mundial de Derechos Humanos, Declaración y programa de acción de Viena, 12 de julio de 1993, [Consultada 5 de agosto de 2017], [Disponible en: http://www.ohchr.org/Documents/Events/OHCHR20/VDPA_ booklet_Spanish.pdf]

${ }^{31}$ Conferencia Mundial de Derechos Humanos, Declaración y programa de acción de Viena, 12 de julio de 1993, [Consultada 5 de agosto de 2017], [Disponible en: http://www.ohchr.org/Documents/Events/OHCHR20/VDPA_ booklet_Spanish.pdf]

32 Franco Cuervo, Juan José, El derecho humano al voto, México, Comisión Nacional de los Derechos Humanos, 2016. [Consulta: 5 de agosto, 2017]. Disponible en: http://appweb.cndh.org.mx/biblioteca/archivos/pdfs/fas-CTDH-Derecho-Voto.pdf
} 
ampliar las posibilidades impugnativas del JDC, acorde a los tratados internacionales, toca a los jueces -mediante su control de convencionalidad-admitir la procedencia del JDC cuando un ciudadano pretenda impugnar el resultado de una votación. Así, se le concederá su derecho a un recurso efectivo que proteja sus derechos humanos de carácter político-electoral.

\section{Conclusión: LA SIGUIENTE LUCHA DEMOCRÁTICA}

En medida que se fortalecen las instituciones que tutelan los derechos humanos, se fortalece la democracia. Esto en virtud de que los derechos humanos y la democracia sostienen una relación de mutua necesidad: sólo una democracia es capaz de consolidar los derechos humanos, y el respeto a los derechos humanos es la condición para que se concrete la democracia.

Entre más grande sea la participación de las personas en los asuntos de su comunidad, en las decisiones de su Estado, será más fuerte el vínculo entre el pueblo y su gobierno. Si existe una mayor inclusión de las demandas sociales en el plan de desarrollo nacional, se amplía la representación de cada sector de la población ante el gobierno y se permite la participación, que es la piedra angular de la democracia.

Existe ya un reconocimiento convencional de los derechos político-electorales en favor de los ciudadanos, pero, además, se debe resaltar el reconocimiento de un derecho a contar con un recurso efectivo. Por ello, nuestro país debe tener un medio que permita a los ciudadanos impugnar los resultados de una elección, en defensa de sus derechos político-electorales y en particular, de su derecho al voto.

Por el momento, sólo existe un medio de defensa contra violaciones individuales a tales derechos -el JDC- pero el mismo se agota en la emisión del voto. Más allá de esto, el voto ciudadano queda a merced de la decisión de los dirigentes partidistas, quienes pueden optar por impugnar o no las posibles violaciones al voto ciudadano, una vez que está en las urnas.

206 Si la tutela del voto emitido por los ciudadanos no estuviera delegada en las dirigencias partidistas, se permitiría que todo ciudadano inconforme con la suerte de su voto, participara activamente en la defensa. Lo anterior armoniza con dotar al ciudadano de un recurso efectivo, como exigen los tratados internacionales, pero, además, armoniza con la esencia de la democracia, que es la participación ciudadana.

Después de 21 años de disponer de un sistema de medios de impugnación en materia electoral, la experiencia nos muestra que, tras cada proceso 
electoral, existe una gran cantidad de controversias y encono social por los resultados. Si la sociedad contara con un recurso efectivo en materia político-electoral, que le permitiera denunciar irregularidades en la casilla donde votó, o bien, documentar con las nuevas tecnologías las posibles violaciones a la esfera jurídica de su voto - con seguridad- los ciudadanos aportarían mayores elementos probatorios a los litigios electorales, lo que esclarecería los resultados y probablemente, aminoraría los enconos.

Hasta ahora, las disputas poselectorales se han llevado a cabo a nivel jurisdiccional. Es menester que sigan ahí y no en las calles, con protestas que pueden devenir en violencia. Por ello, cada vez es más fuerte la demanda para que los ciudadanos estén legitimados en la impugnación directa de los resultados electorales. Esa es la siguiente lucha democrática que se necesita.

\section{Bibliografía}

Bernal, BeAtriz, Memoria del IV Congreso de Historia del Derecho Mexicano (1986), México, unam, 1988.

Carpizo, Jorge, Concepto de democracia y sistema de gobierno en América Latina, México, unam, 2007.

“Conferencia Mundial de Derechos Humanos, Declaración y programa de acción de Viena”, 12 de julio de 1993.

"Constitución Política de los Estados Unidos Mexicanos, México, 5 de febrero de 1917", Diario Oficial de la Federación, 24 de febrero, 2017.

“Convención Americana sobre Derechos Humanos (Pacto de San José)”, Costa Rica, 1969.

“Declaración Americana de los Derechos y Deberes del Hombre”, Colombia, 1948.

Franco Cuervo, Juan José, El derecho humano al voto, México, Comisión Nacional de los Derechos Humanos, 2016.

“Justicia Electoral”, Revista del Tribunal Electoral del Poder Judicial de la Federación, suplemento 6, tercera época, año 2003.

"Ley General del Sistema de Medios de Impugnación en Materia Electoral, México, 22 de noviembre de 1996", Diario Oficial de la Federación, 23 de mayo, 2014.

Mariani, Rodolfo, Democracia/Estado/Ciudadanía: Hacia un Estado de y para la Democracia en América Latina, Perú, Programa de la Naciones Unidas para el Desarrollo (PNUD), 2008.

Mercader Díaz De León, Antonio, Derecho electoral mexicano: el juicio electoral ciudadano y otros medios de control constitucional, México, Porrúa, 2006. 
Merino, Mauricio, La participación ciudadana en la democracia, México, ife, 2001. Naciones Unidas, “Declaración Universal de Derechos Humanos, Nueva York, 1948”. O’Donnell, Guillermo, "Democracia Delegativa”, Journal of Democracy en Español, vol. 5, núm. 1.

O’Donnell, Guillermo, “Rendición de cuentas horizontal y nuevas poliarquías”, $R e$ vista Nueva Sociedad, núm. 152, 1997.

Olvera, Alberto, Ciudadanía y democracia, México, ife, 2008.

"Pacto Internacional de Derechos Civiles y Políticos”, Nueva York, 1966.

Patiño Manffer, Ruperto y Ríos Ruíz, Alma de los Ángeles, Derecho Electoral. Temas de Actualidad, México, Porrúa - UNAM, 2011.

Programa de las Naciones Unidas para el Desarrollo, la democracia en América Latina. Hacia una democracia de ciudadanas y ciudadanos. El debate conceptual sobre la democracia, Perú, Programa de las Naciones Unidas para el Desarrollo, 2004.

Real Academia Española y Consejo General del Poder Judicial, Diccionario del español jurídico, Madrid, Espasa, 2016.

Real Academia EsPañola, Diccionario de la lengua española, Madrid, Espasa, 2014.

Resolución A/RES/62/7, Organización de las Naciones Unidas, Nueva York, 08 de noviembre, 2007.

SÁchica, LuIS CARlos, Democracia, representación y participación, Costa Rica, Instituto Interamericano de Derechos Humanos - Capel, 1985. 